\begin{tabular}{|c|}
\hline 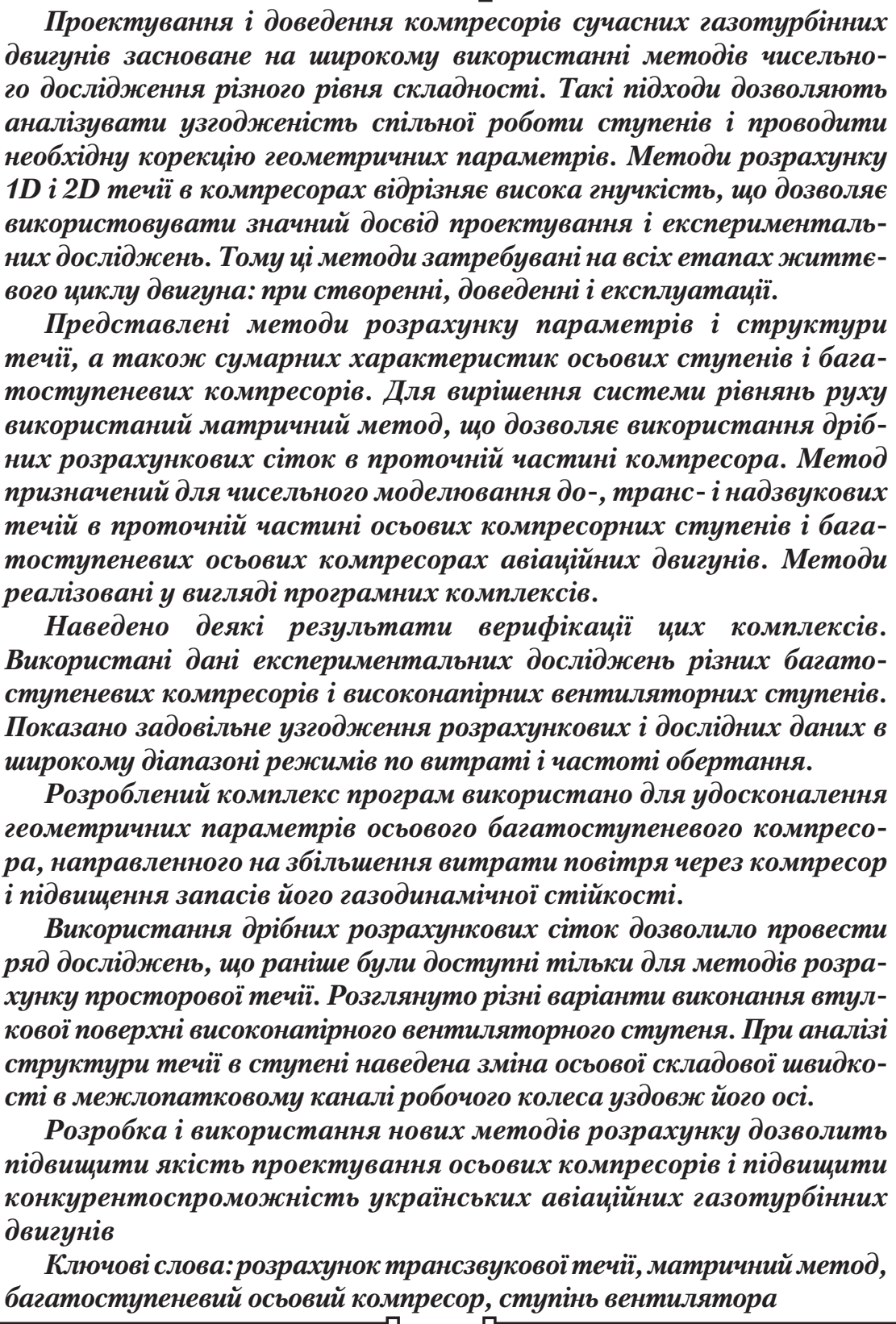 \\
\hline
\end{tabular}

UDC 621.45

DOI: $10.15587 / 1729-4061.2018 .139445$

\section{NUMERICAL STUDY OF FLOWS IN AXIAL COMPRESSORS OF AIRCRAFT GAS-TURBINE ENGINES}

\author{
L. B o y k o \\ Doctor of Technical Sciences, \\ Professor* \\ E-mail: I.boyko@khai.edu \\ A. D yom in \\ $\mathrm{PhD}$, Senior Researcher* \\ E-mail: a.dyomin@khai.edu \\ *Department of aviation \\ engines theory \\ National Aerospace University \\ named after M. Zhukovsky \\ "Kharkiv Aviation Institute" \\ Chkalova str., 17, Kharkiv, \\ Ukraine, 61070
}

\section{Introduction}

The process of design of compressors for modern gas turbine engines is based on the wide use of numerical analysis methods that are divided into methods of verification and design calculation. These approaches seek to solve, respectively, the direct and inverse problem in the theory of turbomachines.

Methods of verification enable determining the flow structure and the summary characteristics of a multistage compressor, as well as its elements. Their application makes it possible to analyze the consistency of compressor stages work and to perform the necessary correction of geometrical parameters.

At different stages of the design process preference is given to different approaches to flow modeling. Both the methods for calculating flows with the mass-averaged parameters in a one-dimensional (1D) setting and the spatial flow analysis methods (3D) could be employed.

Based on the predefined geometrical parameters of blade rows at a mean radius and the flow-through part, the one-dimensional approaches are applied to analyze gas-dynamic parameters and characteristics of separate stages, of the multistage compressors. They are widely used in order to improve the geometry of blade rows. High flexibility of these methods, which makes it possible to employ considerable experience of designing, as well as the results of experimental research, explains why these methods are indispensable at all stages of the engine life cycle: when assembling, adjusting, and operating.

Using the $2 \mathrm{D}$ axisymmetric approaches to calculating the flow at compressors provides efficiency sufficient for practical implementation. This is especially important when undertaking a large volume of research in order to optimize parameters. 
In this case, designers prefer the verified software packages for the calculation of flow.

The result of calculating a three-dimensional viscous flow is the defined structure of spatial flow in the bladeto-blade channels, which reflects the existence of eddy formations, detachments, and the non-homogeneous flow parameters. Currently, this is a dominating direction; the availability of 3D computations becomes an important element of scientific research. The widespread commercially available software packages include ANSYS (United States), NUMECA (Belgium), FlowVision (Russia), FlowER (Ukraine).

Despite a slight decline, in recent years, in public interest in the methods for calculating the 1D and 2D flows, such approaches are actively used in the practice of design of blade machines for various purposes. These approaches are an integral part that accompanies the specialized software packages, which emphasizes the importance of developing new, as well as improving existing, calculation methods and appropriate software systems.

\section{Literature review and problem statement}

At present, in the process of designing multi-stage compressors, most engine-building firms carry out the greatest amount of calculation operations using the methods for calculating a two-dimensional axisymmetric flow. Performance speed, reliability, a possibility to employ empirical dependences and obtain comprehensible results - all this renders these methods necessary for the detailed analysis of characteristics and parameters of flow at multi-stage compressors. Therefore, it is an important task to develop and improve existing methods of calculation. The possibility of numerical simulation of flow at a multistage axial compressor over a wide range of modes is of great importance to ensure its reliable operation.

The most widespread methods in the calculation of axisymmetric flow are the curvature methods of streamlines (CSL) and matrix methods. These methods are fast, reliable, they make it possible to easily introduce to calculation empirical data on losses and angles of lag.

Among the best-known studies that address the development and application of a CSL method to calculate flows at turbomachines are the classical articles that outline basic provisions of a given method [1, 2]. These works served as a foundation for the further development of this field. The main disadvantages of a given approach include the complexity of using small computational grids when building a current line.

Development of effective software systems based on CSL contributed to the success of numerical simulation at multi-stage compressors. At present, software systems based on CSL are widely used by leading aero engine manufacturing firms.

Improving the CSL methods is currently aimed at widening the range of its application for trans- and supersonic flows at axial compressors. Article [3] described an approach, based on CSL, which employs a physically substantiated model to determine the losses and angles of flow lag. Using a given approach allowed the authors to carry out research into a two-stage blower at the flow Mach numbers exceeding $M=1.5$ [4]. The development of CSL for transonic flow velocities (high subsonic and low supersonic) is reported in [5]. The application of CSL in combination with a dif- fuser criterion enables the estimation of a resistance limit for a multi-stage axial compressor [6]; it also makes it possible to explore the effect of water injection [7] to the flow-through part of compressor.

In the matrix method, a solution is searched for at a fixed grid while the equations recorded using a function of current (FC) are reduced to the second order differential equation. The advantage of a given approach is a possibility of using small quasi-orthogonal grids, which provide for a detailed pattern of flow at the blade-to-blade channels of turbomachines. The basics of the method were laid down in the 1950-60ies [8]. Employing the concept of "artificial compressibility", proposed in article [9] and developed in study [10], made it possible to extend the scope of application of the matrix method to cover the transonic flow velocities. In article [11], the use of "artificial compressibility", when applying the matrix approach, enabled the overcoming of the speed of sound. Although numerical methods based on FT have not been employed as common as CSL methods, a possibility to use smaller grids when calculating flows at turbomachines attracts at present a growing number of researchers [12,13].

The widespread use of axisymmetric methods for the calculation of flows at aero-engine compressors during design largely determines a direction for the development of these approaches. The increasing flow velocities at a flowthrough part in the blade-to-blade channels necessitates the simulation of supersonic flows. The use of a complex spatial profiling of blades at compressors defines, in turn, the need for their detailed description, which is provided by the application of smaller grids.

\section{The aim and objectives of the study}

The aim of this study is to improve the geometrical parameters of blade rows and the flow-through part of axial compressor stages, as well as multistage axial compressors, using the developed system of calculation verification methods.

To achieve the set aim, the following tasks have been solved:

- to develop a calculation method for subsonic, transonic, and supersonic flow at axial multistage axial compressors of aircraft engines and elements and to perform its verification;

- to develop a calculation method for the characteristics of multi-stage axial compressors of aircraft engines and to perform its verification;

- to improve compressor stages and multistage axial compressors using the developed methods of calculation.

\section{Numerical methods for studying flows at axial isolated stages and multi-stage axial compressors of GTE}

4. 1. The method for calculating the summary characteristics and the structure of two-dimensional subsonic and transonic flow

Scientists at the Department of Theory of Aircraft Engines of the National Aerospace University Kharkov Aviation Institute (Kharkov, Ukraine) designed a software system to simulate flows at aircraft engine compressors. It includes methods for $1 \mathrm{D}$ and $2 \mathrm{D}$ analyses of parameters and structure of flow. 
The following calculation verification method for a 2D flow and the software package (SP) that implements it, AxSym (Ukraine), was devised by Authors. SP AxSym makes it possible to define the structure of the flow, averaged in circumferential direction, at a compressor stage, at a unit of stages, at multi-stage compressors, as well as in the supply and discharge channels. The scope of application of the developed method is limited to the subsonic and transonic (to $M=1.4$ ) flow modes.

When constructing methods for the calculation of transonic flows at blade machines, traditionally used is the principle of time-based establishment applying a solution to the system of gas dynamics equations, recorded in the nonstationary form. This helps ensure steady end-to-end account throughout the flow. Such an approach is universal; its application is justified when there are powerful surges in compaction and their interaction. However, if a flow supersonic speed is low $(M<1.4)$, an alternative to the establishing methods might be a solution to the system of gas dynamics equations in the stationary form. To ensure the stability of calculation at $M \geq 1.0$, one introduces, similarly to several known articles [14, 15], a correction for density in the form of artificial compressibility.

The system of equations describing the motion of a perfect compressible gas is recorded for the coordinate system that rotates at a constant angular velocity $\omega$ :

$$
\begin{aligned}
& \vec{\nabla} \cdot(\rho \vec{w})=0 ; \\
& (\vec{\omega} \cdot \vec{\nabla}) \vec{w}+2 \vec{\omega} \times \vec{\omega}+\vec{\omega} \times \vec{u}+\frac{1}{\rho} \vec{\nabla} p=0 ; \\
& \vec{\nabla} \cdot[\vec{\omega}(\rho E+p)]=0,
\end{aligned}
$$

where $\vec{\nabla}$ is the differential Hamilton operator; $\rho$ is the density; $\vec{w}, \vec{\omega}, \vec{u}$ are the vectors of relative velocity, angular and circumferential velocity of rotor rotation, respectively; $p$ is pressure, specific total energy

$$
E=c_{v} T+\frac{w^{2}-u^{2}}{2}
$$

where $T$ is the temperature; $c_{v}$ is the heat capacity at a constant volume.

To close the system, we used an equation for the perfect gas state

$$
p=\rho R T
$$

Upon averaging the system of equations in the circumferential direction, in order to solve a problem, we employed a system of generalized coordinates $(\xi, \eta, \varphi)$, shown in Fig. $1, a$. In a given system, the $\varphi$ axis coincides with the circumferential direction with the $\xi$ and $\eta$ axes located in a meridional plane so that the boundaries of an integration region coincide with lines of $\xi$ and $\eta=$ const. The physical region is mapped onto a rectangular calculation area $A B C D$ (Fig. 1, $b$ ), covered with a uniform computational grid with step $\Delta \xi=\Delta \eta=$ const.

It is possible, at boundaries $A B$ and $C D$, to assign boundary conditions of two types: the distribution of current density or the angle of inclination of streamlines to the axis of a turbomachine along radius $\left(\rho v_{a}\right)=f(r)$ or $g=f(r), v_{a}$ is the velocity axial component.
We assign the non-flow conditions at hub surface $A D$ and peripheral surfaces $B E$ and $F C$, Fig. 1. The air bleeding (bypass) from the flow-through part is performed at section EF.

In order to transform further, equation of motion (2) is given in the energy form:

$$
\vec{w} \times(\vec{\nabla} \times \vec{v})=\vec{\nabla} H-T \vec{\nabla} S,
$$

where $\vec{v}$ is the vector of absolute velocity;

$$
H=c_{p} T+\left(w^{2}-u^{2}\right) / 2
$$

is the flow rothalpy, $S$ is entropy.

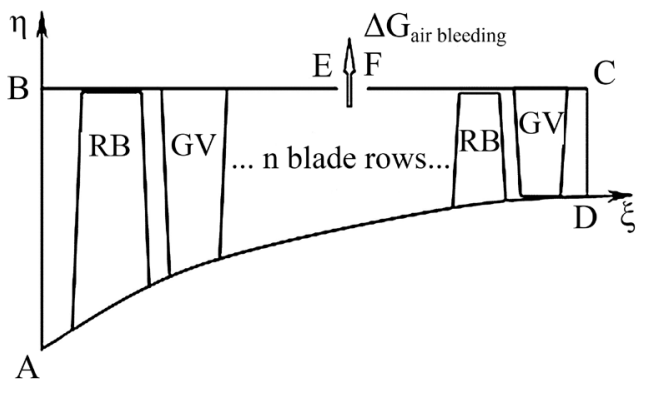

$a$

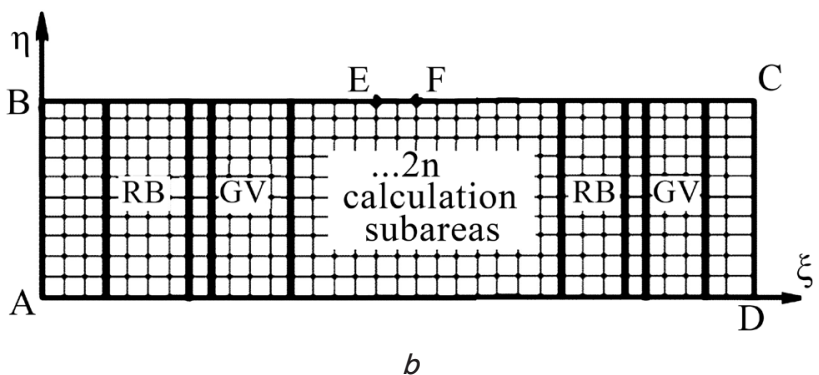

Fig. 1. Calculation region: $a-$ physical region; $b-$ calculation subarea

Modeling the actual flow properties is carried out through the introduction, similar to shown in article [14], to the right side of equation (5) of an additional term, which simulated the dissipative flow properties:

$$
\vec{w} \times(\vec{\nabla} \times \vec{v})=\vec{\nabla} H-T \vec{\nabla} S-\vec{D} .
$$

Vector $\vec{D}$, as an analog to the forces of friction, is directed in the opposite direction from the relative velocity vector, and is determined from the condition for a complete transition of the work of friction forces into heat:

$$
\vec{D}=\vec{\omega} D / \omega, \quad \vec{D} \cdot \vec{\omega}=T \vec{\omega} / \vec{\nabla} S .
$$

The technique for accounting for the viscous flow properties at blade rows, employed in the calculation method, implies the computation during iterations of complete pressure losses and the flow lag angles in the grid.

The magnitude of total losses at an arbitrary cross section along the radius of a blade crown is accepted to be equal to the sum of constituent losses:

$$
\zeta_{\Sigma}=\zeta_{\text {profil }}+\zeta_{\text {shock }}+\zeta_{\text {second }}+\zeta_{\text {tip }}+\zeta_{\text {tip clear. }} .
$$


To determine the components in equation (8), we applied semi-empirical dependences. Profile losses are determined in accordance with [15], shock - [16, 17], secondary, tip, and those in the tip clearance, are determined according to $[18,19]$.

Estimation of losses in the shock waves at flow supersonic speeds at the inlet to the grid is carried out in accordance with the one-step model by Hartman-Lewis [20], which holds at relatively low supersonic speeds of flow at the inlet.

Flow parameters, obtained from calculations at various radii, are averaged, using the laws of conservation of mass, energy, and entropy, which ensures deriving the values for integral parameters of flow for blade rows, stages, and compressor in general.

The source data for calculation are the geometrical parameters of the flow-through part, blade rows, and a mode of operation (air flow rate and the rotor rotation frequency). In addition, we assign radial distributions of the flow parameters at the inlet to the estimated region (the pressure and temperature of stalled flow $P_{H}^{*}, T_{H}^{*}$, as well as the angle of flow entry at absolute motion $-\alpha$ ).

Using small quasi-orthogonal computational grids, characteristic of the matrix methods, makes it possible to describe in detail the flow-through part and blade surfaces. Values for the geometrical parameters of blade rows, assigned in the source data, are approximated for all nodes in the grid.

Calculation algorithm is implemented in the software package AxSym [21], which allows carrying out the verification calculations of the subsonic and transonic axisymmetric flow in the flow-through part at axial multistage compressors with the selection and bypass of air.

Fig. 2-4 show the example of certain results obtained by numerical simulation of flow at multistage axial compressors, which we hereafter refer to as compressor "1", compressor " 2 ", and compressor " 3 ".

Fig. 2 shows the calculated summary characteristics of a six-stage axial compressor from an aircraft engine (compressor "1") in comparison with data from experimental study [22].

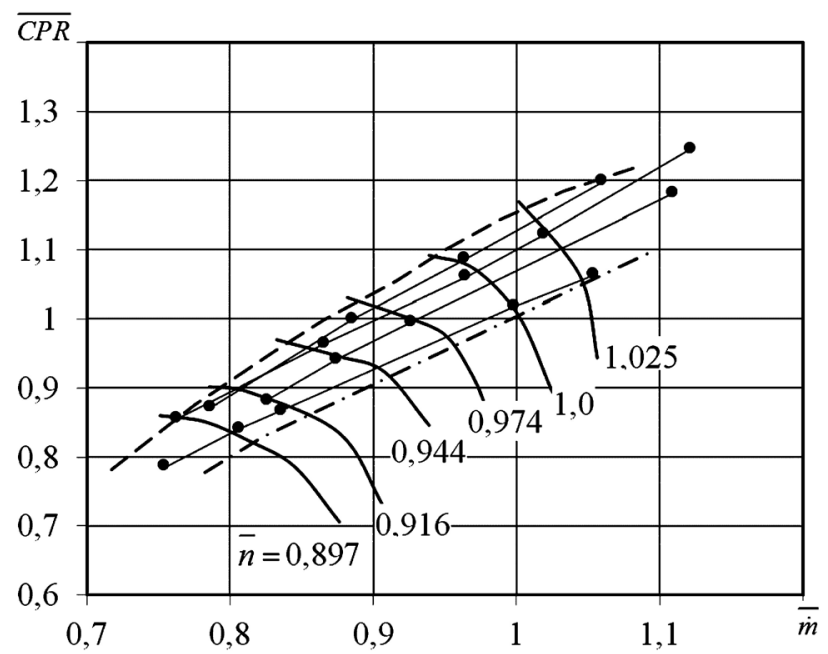

Fig. 2. Summary characteristic of a multi-stage axial compressor (compressor "1") — - calculation by

AxSym; $\bullet-$ experimental data [22]; -- --_. - boundary of the region of compressor stable operation; - - - - - line of operating modes
Fig. 3 shows the characteristic of a multi-stage axial compressor of high pressure from an aircraft engine (compressor "2") in comparison with experimental data.

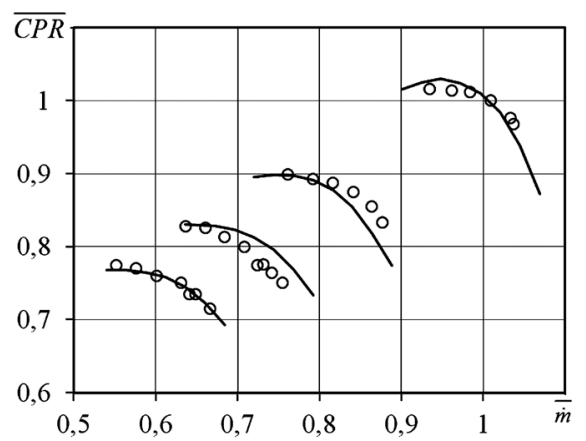

Fig. 3. Summary characteristic of a multi-stage axial compressor (compressor "2"): — — calculation by

AxSym; o- experimental data [23].

Fig. 4 shows the distribution of total temperature and total pressure by radius behind the rotor blades $(\mathrm{RB})$ in compressor " 3 ".
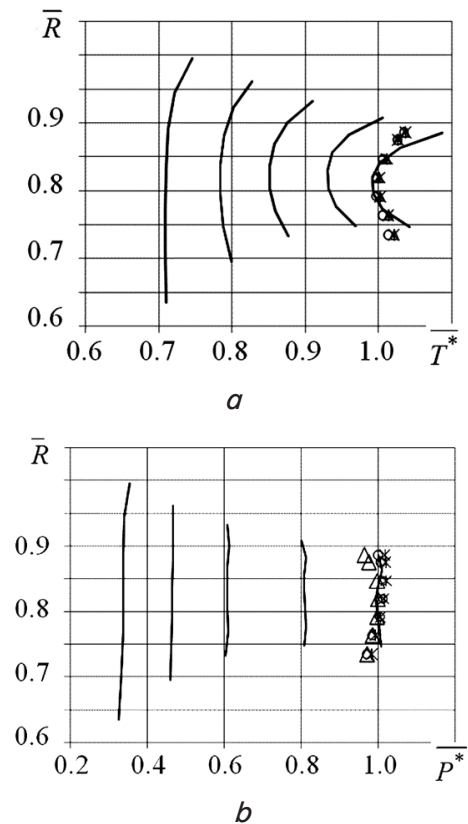

Fig. 4. Distribution of flow parameters along the radius behind stage 5 of compressor " 3 " under mode $\bar{n}=0.9, \overline{\dot{m}}=0.75: a-\bar{T}^{*}=T^{*}{ }_{T_{K}^{*}} ; b-\bar{P}^{*}=P^{*} / P_{K}^{*} ;$

- calculation by AxSym; $\Delta O *$ - experimental data [24]

The verification of SP AxSym presented here demonstrates, regarding compressors of various types of GTE, a satisfactory match between the results of calculation and experimental data.

To calculate the flow at high-head axial compressor stages, which have, under the estimated mode, the supersonic level of flow velocities at the inlet, the reported method was improved. A model of a supersonic flow in the blade-to-blade channel was changed from the one-shock wave to the model with multiple shock waves. Such an approach makes it possible to determine wave losses in the cascades with an arbitrary shape of the mid- 
dle line, and to expand the range of profile shapes that can be described. These improvements are included in the SP AxSym_M [25].

As an example of verification using SP AxSym_M, Fig. 5 shows the summary characteristic of a high-pressure fan in the form of the dependence of a compressor pressure ratio $(\mathrm{CPR})$ on relative mass flow rate. We obtained a satisfactory correlation between calculation results and experimental data.

Another example of verification using SP AxSym_M is the results of numerical simulation of subsonic, transonic, and supersonic flow at the high-pressure impeller ROTOR 37 [27, 28]. Fig. 6 shows its summary characteristic (solid line) in comparison with experimental data (markers) at rotation frequency $\bar{n}=1.0$.

Fig. 7 shows the distributions by radius of flow parameters at the inlet and outlet of rotor blades RB at $\bar{n}=1.0$ under two modes of mass flow rate $\dot{m}=19.6 \mathrm{~kg} / \mathrm{s}$ and $\dot{m}=20.74 \mathrm{~kg} / \mathrm{s}$, obtained by calculation (solid line) in comparison with experimental data (markers). Index " 1 " corresponds to parameters at the inlet, and "2" at the outlet from RB.

The developed method for calculating the axisymmetric flow and the software package that implements it showed stable performance in a wide range of operational modes in terms of consumption and the rotor rotation frequency. The results reported here demonstrate satisfactory agreement between calculation results and data from experimental studies. This confirms the feasibility of using a given approach in order to solve practical tasks.

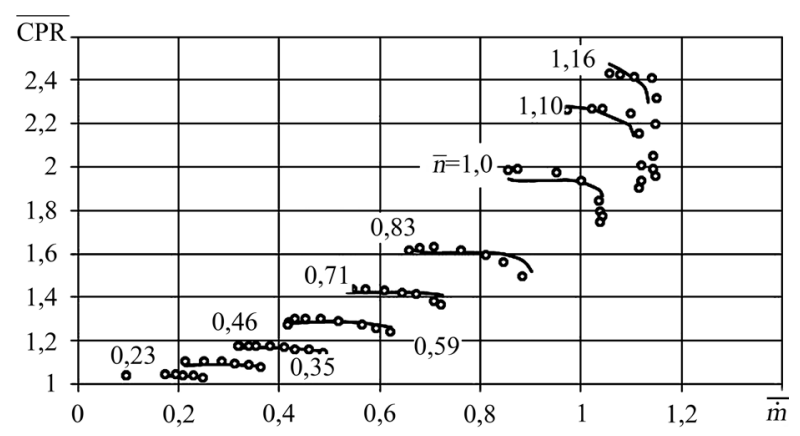

Fig. 5. Characteristic of a high-pressure axial fan stage - calculation by AxSym_M; o - experimental data [26]

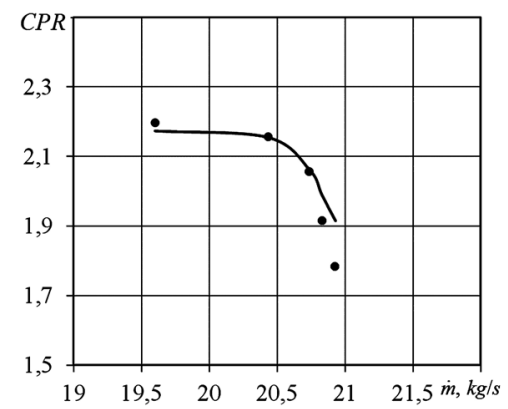

Fig. 6. Characteristic of the impeller ROTOR 37 - calculation by AxSym_M; • - experimental data [27]
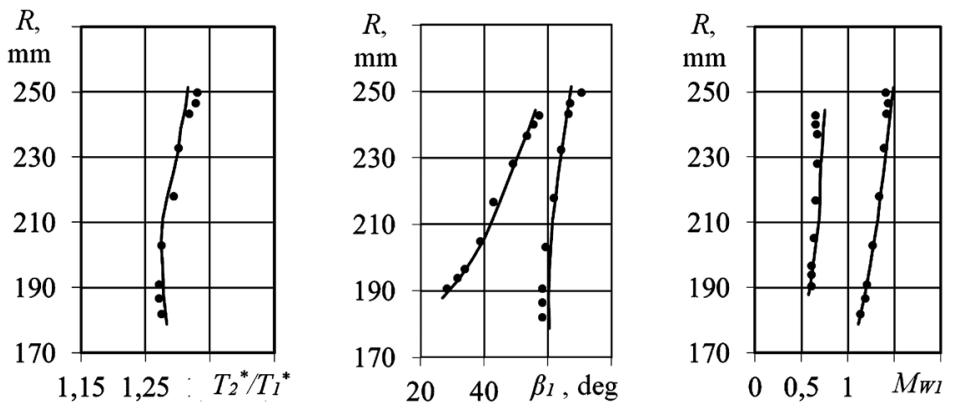

$a$

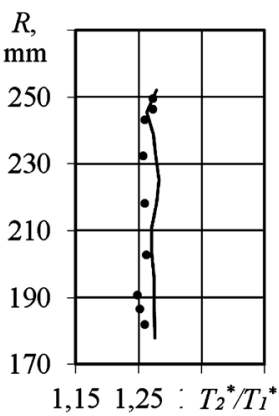

1 -st mode $\dot{m}=19.6 \mathrm{~kg} / \mathrm{s}$

$b$

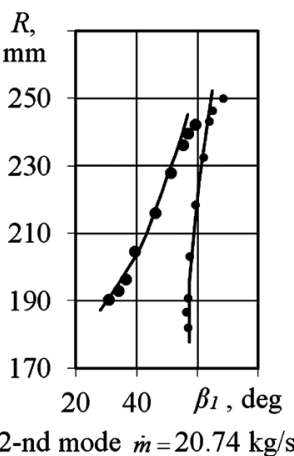

2-nd mode $\dot{m}=20.74 \mathrm{~kg} / \mathrm{s}$

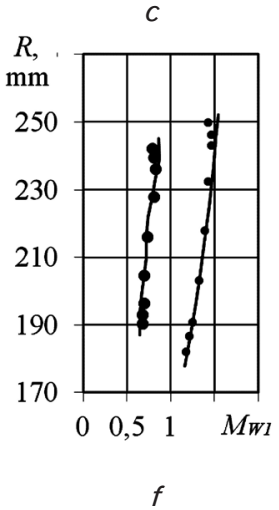

Fig. 7. Simulation of flow in the impeller ROTOR 37 at the estimated rotation frequency at different consumption: $a, d-\mathrm{RB}$ blade height distribution $T_{2}^{*} / T_{1}^{*} ; b, e-$ distribution of flow angles at the inlet and outlet of RB; $c, f$-distribution of Mach numbers of the flow in relative motion at the inlet and outlet of RB; — - calculation by AxSym_M;

- - experimental data [28]

4. 2. Calculation of parameters for an axial multistage compressor at GTE in one-dimensional statement

At the stage of preliminary design, of big importance are the methods for the calculation of blade machines based on the average-mass parameters. Flow is assumed to be stationary, averaged in radial direction and for the blade height.

The method of calculation described below was constructed based on simplifications of the 2D flow calculation method at multi-stage compressors, developed and tested earlier [29]. When constructing it, we used equations for the continuity, motion, the law of preservation of energy and the state of a compressible perfect gas. For rotary blade rows, we applied a record of equations in relative motion. The system of equations is supplemented with ratios in the velocity triangles, employed in the theory of turbomachines.

To account for the manifestations of viscous effects, we introduced procedures for determining coefficients of losses and flow lag angles in the grids, implemented using the generalized semi-empirical dependences. Losses in a blade crown are the result of summation of profile, secondary and resulting losses, as well as losses due to a reflow in the radial gap.

The calculation method makes it possible to obtain thermal-gas-dynamic parameters of blade rows, stages, and compressor in general, to assess the alignment of work under different modes, to consider the impact of air bleeding and bypass, to determine summary characteristics.

Source data for the calculation are the geometrical parameters of the flow-through part and blade rows at the mean radius, the mode of operation (air consumption and the rotor rotation frequency) and flow parameters at the inlet. 
As an example, Fig. 8 shows with solid lines the summary characteristic of a multi-stage axial compressor of low pressure from a modern aircraft engine ("compressor 1"), obtained by applying a given method. Dashed lines in this Figure denote the results of flow calculation when using SP AxSym, which were compared with experimental data (Fig. 2). The obtained satisfactory correlation of estimation data allows us to employ a given method for solving practical tasks.

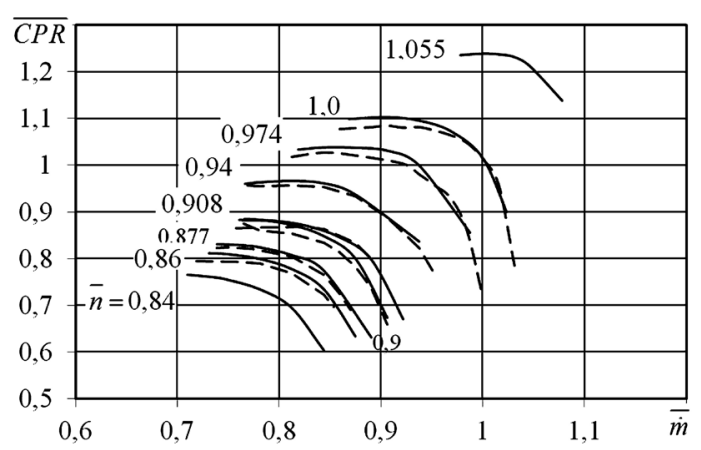

Fig. 8. Summary characteristic of multi-stage axial compressor ("compressor 1"): —— 1D calculation; - - - - calculation by AxSym

This approach has been used in analyzing the impact of changes in the geometrical parameters of blade rows on the summary characteristics of multi-stage axial compressors at modern GTE, as well as in mathematical models of gas-turbine engines of high level [30].

\section{Improvement of geometrical parameters of axial} compressors using the developed numerical methods

\section{1. Modernization of geometrical parameters of axial} multi-stage compressor

If the improvement of GTE parameters is considered, they undergo modernization, which includes the correction of geometrical parameters of its nodes, providing the improvement of engine parameters.

To improve the alignment of stages at multistage axial compressor (MAC), the shape of a profile is changed, which is accompanied by a change in the length of the chord of blades; at the first stage it can be carried out by clipping the blades from the side of input or output edges. To model such changes and to estimate their impact on the parameters of compressor and its characteristics, the most suitable are the methods for calculating $2 \mathrm{D}$ flows and the software systems that implement them.

Next, we demonstrate certain results obtained using SP AxSym at numerical simulation of axisymmetric flow in an axial five-stage compressor. We estimated the impact of change in the shape of profiles of guiding apparatuses on a change in the consumption of air through the compressor at low speeds of the roto rotation, on the flow structure, and summary characteristics. The considered variants of changes in the blades of guide vanes (GV), simulated using SP AxSym, differ from the original compressor (variant " 0 ") by a reduction in the length of the chord from the input and output edges GV1 (variants "1" and "2", respectively) and GV2 (variants " 3 " and "4").

Fig. 9 shows a head characteristic of the examined compressor at a fixed frequency of the rotor rotation. Changes in blade rows at a preset program of control over rotary GV under a given mode for the rotation frequency lead to an offset of the characteristic towards an increase in consumption ("variant 3"). Reduction of the chord from the output edge $2 \mathrm{GV}$ reduces consumption through the compressor. Explanation of these results follows from the velocity triangles at different radii, obtained by calculation, as well as the Mach numbers isolines in the flow-through part in absolute and relative $(\mathrm{RB})$ motion.

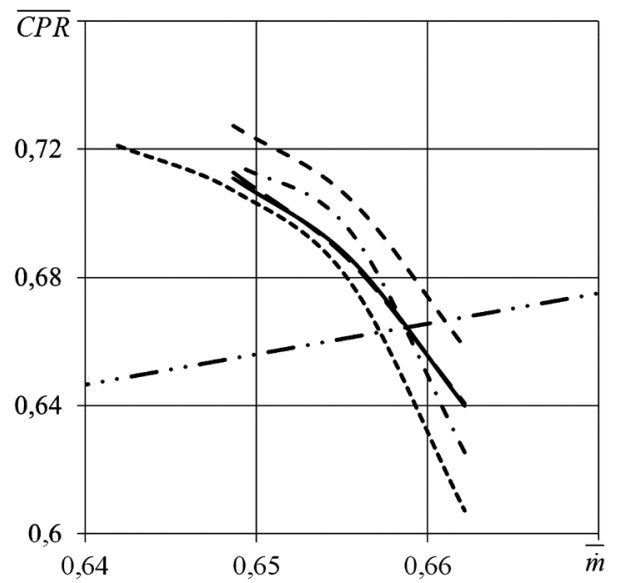

Fig. 9. Head characteristic of multi-stage axial compressor: - original compressor; ---- reduction of chord GV1 (input edge); -.-.- - reduction of chord HA1 (output edge); - - - . - reduction of chord GV2 (input edge);

------. - reduction of chord GV2 (output edge); $-\cdots--$ line of operating modes

Fig. 10 shows isolines of the flow Mach numbers for the original variant of compressor near the line of operating modes.

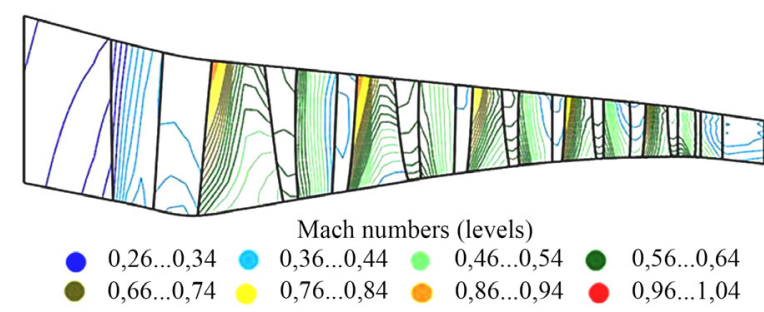

Fig. 10. Isolines of the flow Mach for the original variant of compressor near the line of operating modes

The results of calculation of transonic flows at a multi-stage axial compressor with the modified guiding apparatuses are employed in the further refinement of the compressor.

5. 2. Studying the influence of the shape of a hub surface on the performance of a high-head stage of axial fan

When designing the high-head stages with the degree of increase in pressure greater than 2.0, it is a relevant task to find the rational shapes of flow-through parts. Solving it might involve methods for the calculation of spatial viscous flows. At the same time, modern approaches based on a two-dimensional statement make it possible to obtain useful results. 
For the fan stages of aircraft engines, the widely-used shape of a hub surface is conical, being the most technologically accepted. The development of production technologies enabled the fabrication of other, more complex shape of a bushing surface: convex, concave-convex, and other shapes. Fig. 11 schematically shows different variants for the execution of a hub surface at fan stages of aircraft engines.

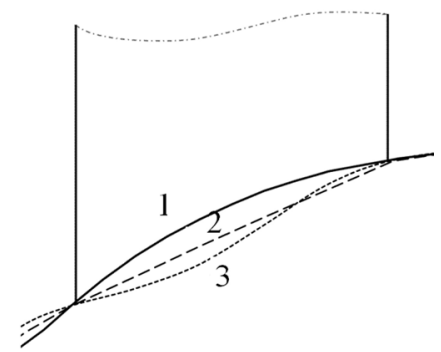

Fig. 11. Variants for the execution of a hub surface of the impeller at a fan stage:

1 - convex; 2 - conical; 3 - concave-convex

Estimation studies have shown that a change in the shape of a hub surface substantially changes the field of flow velocities incident on the blade.

Fig. 12 shows distributions of incident angles on the blade of RB for height under the mode of maximum efficiency. It follows from Fig. 12 that a change in the shape of a hub surface exerts a significant impact on the flow character in the adjacent region due to the rearrangement of the flow at the inlet to RB.

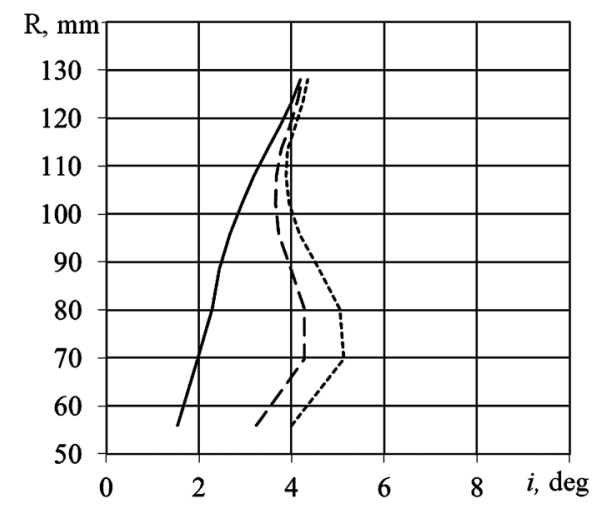

Fig. 12. Distribution of angles incident on the blade for height of RB at a different shape of a bushing surface under the mode of maximum efficiency: _- convex;

- - - - conical; ---- - concave-convex

Fig. 13 shows the characteristic of $\mathrm{RB}$ for a fan stage with a different shape of bushing surface.

The influence of a hub shape on the flow character of RB is clearly shown in Fig. 14. It demonstrates the distribution of an axial velocity component in the blade-to-blade channel of RB for radius for the considered variants in different cross sections along axis $x=0,9,18,36,55,73,82$ and $100 \%$ of the axial length of RB.

Based on the results presented, one can conclude that for the high-head stages of axial compressors at aircraft engines that have small aspect ratio of RB blades, the shape of hub surface exerts a significant impact on the flow structure over the entire height of the blade.
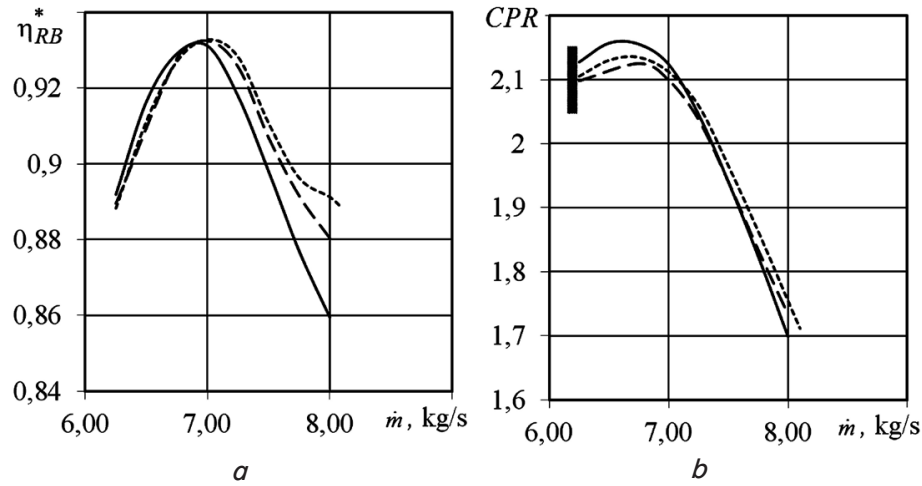

Fig. 13. Characteristic of RB for a fan stage with a different shape of the hub surface: $a$ - dependence of isentropic efficiency of the stage on the mass flow rate through the stage, $\eta_{P K}^{*}=f(\overline{\dot{m}})$;

$b$ - dependence of the total pressure ratio at a stage on the mass flow rate through the stage $\pi_{P K}^{*}=f(\overline{\dot{m}})$; - convex; - - - conical; ---- - concave-convex
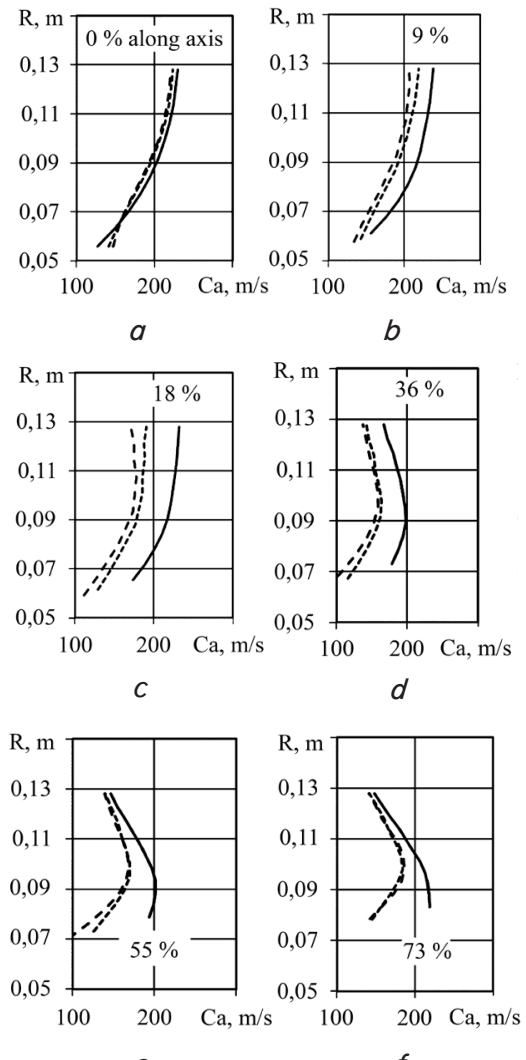

e
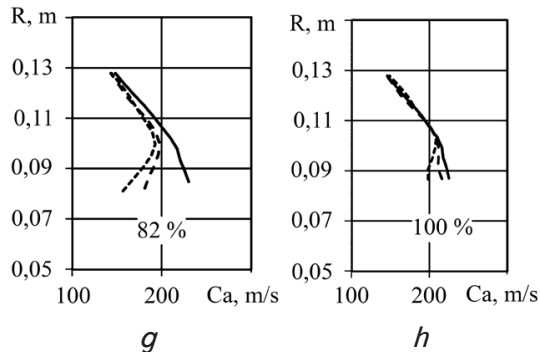

Fig. 14. Distribution of axial velocity in RB along the axis of the compressor under the estimation mode at a different shape of a hub surface: $a-\%$ along the axis; $b-9 \%$; $c-18 \% ; d-36 \% ; e-55 \% ; f-73 \% ; g-82 \%$;

$$
h-100 \% .- \text { convex; - - - conical; }
$$$$
\text { ---u-concave-convex }
$$ 


\section{Discussion of results of studying the flows at axial compressors in aircraft gas-turbine engines}

We report results of the verification and practical application of the calculation methods, developed by Authors, and the corresponding software systems. The materials presented here clearly demonstrate the capability of SP AxSym and AxSym_M for numerical analysis of sub- and transonic flows at axial compressor stages and multistage axial compressors.

Comparison of the presented approaches with the results of experimental studies, reported in various sources [22-26] allows us to argue about the adequacy of the results obtained to the actual physical processes occurring at axial compressors. The differences between the outcomes of computations and data from experimental studies indicate a certain simplification of the real flow in the course of modeling. The influence of a spatial non-stationary character of the current is not accounted for to the full extent, which is a traditional shortcoming for all methods for the calculation of axisymmetric flow. This shortcoming largely determines the direction of further improvement of the proposed method.

The software complexes AxSym and AxSym_M, developed on the basis of the described method of calculation, make it possible to conduct detailed studies into sub- and transonic axisymmetric flow at the flow-through part of axial compressor stages and multistage axial compressors.

Applying small grids to perform calculations ensures a better description of the flow-through part and blade rows, which positively affects results of the calculations.

Software complexes AxSym and AxSym M were employed in parametric studies into fan stages and axial multistage compressors at aero engines. We analyzed the influence of geometric parameters of blade rows and a flow-through part on thermal-gas-dynamic characteristics of these objects and proposed means to enhance their effectiveness.

Here we report results of the verification and practical application of calculation methods developed by Authors, as well as the corresponding software systems. The results obtained could be explained well by the physical processes that occur in the flow-through parts at multistage compressors and compressor stages when blade rows are flown over by a sub- and trans- and supersonic flow. They clearly demonstrate the capability of SP AxSym and AxSym_M to study the flows in such objects numerically.

The obtained satisfactory agreement between calculation results and experimental data is largely provided by the benefits of the employed matrix method. The application of small computational grids for a better description of the shape of a flow-through part and blade rows makes it possible to calculate the flow structure and summary characteristics in a more precise fashion. The proposed method enables the investigation of sub- and supersonic flow in the flow-through part, expands the range of examined objects and the range of operating modes. In addition, the use of refined semi-empirical dependences for losses and the flow lag angle makes it possible to improve the accuracy of the results obtained. It should be noted that the application of a two-surge model in the simulation of supersonic flows restricts the use of the method and the corresponding SP AxSym_M to speeds that correspond to the Mach number $M_{W 1}<1.6$ at the inlet.

The differences between the results of calculations and data from experimental studies adequately identify the drawbacks of the applied numerical method and the cor- responding software systems. Above all, these include a traditional shortcoming in all methods that calculate an axisymmetric flow - an incomplete consideration of the spatial non-stationary character of current. The approach underlying all methods for calculating 2D flows in the meridional plane, flow averaging in radial direction, is the main source of difficulties in conducting estimation studies:

- estimation of secondary flows;

- clarification of calculation results at the ends of blades;

- localization and determining the intensity of compaction jumps at the surface of the profile when it is flown over by a transonic flow.

One can also highlight the complexity of simulating the modes near the maximum consumption (boundaries of locking), as well as effects associated with a turbulent exchange. These shortcomings define the direction of further improvement of the calculation method presented, as well as the corresponding software package.

Further development of the calculation method is also largely defined by the requirements of enterprises that design and manufacture aircraft engines. Thus, in the framework of projects that involve the engine-building enterprises of Ukraine, the software complexes AxSym and AxSym_M were applied in the course of parametric studies into fan stages and axial multistage compressors at aero engines. We analyzed the influence of geometrical parameters of blade rows and the flow-through part on the thermal-gas-dynamic characteristics of these objects and proposed measures to improve their effectiveness.

\section{Conclusions}

1. We have constructed a calculation method, which makes it possible to determine the structure of an axisymmetric sub-and transonic flow and summary characteristics of high-head compressor stages and multistage axial compressors at aircraft engines; its verification has been performed. We obtained a satisfactory agreement between calculation results and experimental data for a large number of objects over a wide range of modes of consumption and rotation frequency. Comparison was conducted for the summary characteristics and distributions of flow parameters for the height of a flow-through part both for multistage axial compressors and isolated compressor stages.

2. We have developed a method for the calculation of characteristics for multi-stage axial compressor at aircraft engines based on the average-mass parameters, which makes it possible to take into consideration the geometrical parameters of blade rows and the flow-through part; its verification has been performed. We compared calculation results of the flow thermal-gas-dynamic parameters at a multi-stage axial compressor with the calculation results of axisymmetric flow over a wide range of modes. A satisfactory agreement was obtained. A given method could be used both independently and as a component of another calculated model.

3. Software complexes AxSym and AxSym_M were employed for the improvement of geometrical parameters of the axial multi-stage compressor at a modern aircraft engine and of the high-head fan stage:

- we studied the influence of changes in the geometrical parameters of blade rows on the structure of current and the summary characteristics of compressor. Various 
variants of change in the shape of compressor blades were investigated with the aim to enhance the reserve of gas-dynamic stability and to increase the flow of air through the compressor. The limit of steady performance for each variant was estimated using a diffuser factor;

- we have explored the influence of shape of the bushing surface of a high-head fan stage on its characteristics and the distribution of thermal-gas-dynamic parameters along the flow-through part. Here we show a significant impact of the shape of a bushing surface on the flow structure and the summary characteristics of the studied stage. Using a concave-convex shape of the bushing surface made it possible to improve efficiency of the stage compared to a convex shape. Studying the structure of the axisymmetric flow inside a blade-to-blade channel has shown a possibility to build a flow-through part of the stage with a preset gradient of flow parameters along the axis of the compressor stage.

\section{References}

1. Smith Jr. Uravnenie radial'nogo ravnovesiya turbomashiny // Energeticheskie mashiny i ustanovki. 1966. Vol. 88, Issue 1. P. $1-14$.

2. Novak Dzh. Metod krivizny liniy toka v vychislitel'nyh zadachah dlya potoka zhidkosti // Energeticheskie mashiny i ustanovki. 1967. Issue 4. P. 30-41.

3. Boyer K. M., O'Brien W. F. An Improved Streamline Curvature Approach for Off-Design Analysis of Transonic Axial Compression Systems // Volume 5: Turbo Expo 2002, Parts A and B. 2002. doi: https://doi.org/10.1115/gt2002-30444

4. Boyer K. M., O’Brien W. F. Application of an Improved Streamline Curvature Approach to a Modern, Two-Stage Transonic Fan: Comparison With Data and CFD // Volume 5: Turbo Expo 2002, Parts A and B. 2002. doi: https://doi.org/10.1115/ gt2002-30383

5. Tiwari P., Stein A., Lin Y.-L. Dual-Solution and Choked Flow Treatment in a Streamline Curvature Throughflow Solver // Volume 7: Turbomachinery, Parts A, B, and C. 2011. doi: https://doi.org/10.1115/gt2011-46545

6. Development of an Improved Streamline Curvature Approach for Transonic Axial Compressor / Xiaoxiong W., Liu B., Lei S., Guochen Z., Xiaochen M. // Volume 2C: Turbomachinery. 2016. doi: https://doi.org/10.1115/gt2016-57072

7. Matzgeller R., Pichler R. Modeling of Discrete Tip Injection in a Two-Dimensional Streamline Curvature Method // Volume 8: Turbomachinery, Parts A, B, and C. 2012. doi: https://doi.org/10.1115/gt2012-69554

8. Marsh H. A digital computer program for the throughflow fluid mechanics in an arbitrary turbo machine using a matrix method. Aeronaut. Res. Counc. Reports and Memoranda. No. 3509. 1968. 34 p.

9. Mermen E., Saut Dzh., Hafez M. Primenenie metodov iskusstvennoy szhimaemosti dlya chislennogo resheniya polnogo uravneniya potenciala v transzvukovom diapazone skorostey // Raketnaya tekhnika i kosmonavtika. 1979. Vol. 17, Issue 8. P. $50-58$.

10. Hafez M., Louvell D. Chislennoe reshenie uravneniya dlya funkcii toka v sluchae transzvukovyh skorostey // Aerokosmicheskaya tekhnika. 1983. Vol. 1, Issue 11. P. 63-73.

11. Kosolapov Yu. S. Raschet stacionarnyh do- i transzvukovyh nepotencial'nyh techeniy ideal'nogo gaza v osesimmetrichnyh kanalah // Zhurn. vychisl. matem. i matem. fiz. 1989. Vol. 29, Issue 5. P. 765-774.

12. Petrovic M. V., Wiedermann A., Banjac M. B. Development and Validation of a New Universal Through Flow Method for Axial Compressors // Volume 7: Turbomachinery, Parts A and B. 2009. doi: https://doi.org/10.1115/gt2009-59938

13. Banjac M., Petrovic M. V., Wiedermann A. Multistage Axial Compressor Flow Field Predictions Using CFD and Through-Flow Calculations // Volume 2C: Turbomachinery. 2016. doi: https://doi.org/10.1115/gt2016-57632

14. Bosman C., Marsh H. An Improved Method for Calculating the flow in Turbo-Machines, Including a Consistent loss Model // Journal of Mechanical Engineering Science. 1974. Vol. 16, Issue 1. P. 25-31. doi: https://doi.org/10.1243/jmes_ jour_1974_016_006_02

15. Lieblein S. Loss and stall analysis of compressor cascades // ASME Transactions, Journal of Basic Engineering. 1959. Vol. 81. P. 387-400.

16. Al-Daini A. J. Loss and deviation model for a compressor blade element // International Journal of Heat and Fluid Flow. 1986. Vol. 7, Issue 1. P. 69-78. doi: https://doi.org/10.1016/0142-727x(86)90046-9

17. Sven V. K. Prakticheskiy metod rascheta harakteristik okolozvukovogo kompressora // Tr. amer. obshch-va inzh.-mekh. Ser.: Energeticheskie mashiny i ustanovki. 1961. Vol. 83, Issue 3. P. 130-141.

18. Novikov A. S., Shebakpol'skiy F. Ya. Raschet koefficienta vtorichnyh poter' v stupeni osevogo kompressora // Uchenye zapiski CAGI. 1978. Vol. IX, Issue 5. P. 116-119.

19. Koh S. S., Smit L. H. Istochniki i velichiny poter' v osevyh kompressorah // Tr. amer. obshch-va inzh.-mekh. Ser.: Energeticheskie mashiny i ustanovki. 1976. Issue 3. P. 128-145.

20. Miller G. R., Lewis G. W., Hartmann M. J. Shock Losses in Transonic Compressor Blade Rows // Journal of Engineering for Power. 1961. Vol. 83, Issue 3. P. 235. doi: https://doi.org/10.1115/1.3673182 
21. Boyko L. G., Demin A. E., Kovalev M. A. Komp’yuternaya programma AxSym. Rishennia pro reiestratsiyu No. 3570 vid 23.10.2017.

22. Regulirovanie mnogostupenchatogo osevogo kompressora na osnove dvumernogo analiza techeniya / Boyko L. G., Demin A. E., Maksimov Yu. P., Ahtemenko Yu. F. // Trudy XVI Mezhdunarodnoy nauchno-tekhnicheskoy konferencii po kompressornoy tekhnike. Sanct-Peterburg, 2014. Vol. 1. P. 318-327.

23. Raschetnoe issledovanie techeniya v osecentrobezhnom kompressore aviacionnogo GTD / Boyko L. G., Barysheva E. S., Demin A. E., Drynov O. N. // Vestnik Ufimskogo gosudarstvennogo aviacionnogo tekhnicheskogo universiteta. 2013. Vol. 17, Issue 4 (57). P. 29-37.

24. Metod raschetnogo issledovaniya 2D-techeniya v mnogostupenchatyh osevyh kompressorah aviacionnyh dvigateley / Boyko L. G., Demin A. E., Drynov O. N., Kalyuzhnaya V. A. // Vestnik UGATU. 2015. Vol. 19, Issue 1 (67). P. 3-12.

25. Basov Yu. F., Boyko L. G., Demin A. E. Sovershenstvovanie metoda rascheta techeniya v vysokonapornoy kompressornoy stupeni // Aviacionno-kosmicheskaya tekhnika i tekhnologiya. 2009. Issue 2. P. 63-68.

26. Basov Yu. F., Demin A. E., Maksimov Yu. P. Analiz aerodinamicheskih harakteristik i struktury techeniya v transzvukovoy kompressornoy stupeni // Aviacionno-kosmicheskaya tekhnika i tekhnologiya. 2005. Issue 2. P. 37-41.

27. Reid L., Moore R. D. Design and Overall Performance of Four Highly Loaded, High-Speed Inlet Stages for an Advanced High Pressure Ratio Core Compressor // NASA Technical Paper 1337. 1978. 132 p.

28. Reid L., Moore R. D. Performance of Single Stage Axial Flow Transonic Compressor With Rotor and Stator Aspect Ratios of 1.19 and 1.26, Respectively, and With Design Pressure Ratio of 2.05 // NASA Technical Paper 1659. 1980. 104 p.

29. Metod raschet dvumernogo techeniya v mnogostupenchatom osevom kompressore / Boyko L. G., Girich G. D., Ershov V. N., Yanevich V. N. // Izvestiya VUZov. 1989. Issue 5. P. 37-41.

30. Boyko L. G., Karpenko E. L., Akhtemenko U. F. Method of calculating GTE gas-thermodynamic parameters with blade row description of an axial multistage compressor // VESTNIK of the Samara State Aerospace University. 2013. Issue 3 (41). P. 31-39. doi: https://doi.org/10.18287/1998-6629-2013-0-3-2(41)-31-39 